\title{
DE MI TIERRA (DE EMILIA PARDO BAZÁN) Y SUS FANTASMAS*
}

\author{
Isabel Burdiel \\ Universitat de València
}

DOI: $10.17075 /$ iftpc.2021.007

* Este trabajo se ha realizado en el marco del proyecto HAR2014-53802-P, Construcciones del yo: narraciones y representaciones del sujeto moderno. Entre lo personal y lo colectivo, siglos XVII-XIX. Algunas de las reflexiones más literarias del ensayo fueron ofrecidas como homenaje a Jim Amelang en Fernando Andrés / Mauro Hernández / Saúl Martínez (eds.) (2019): Mirando desde el puente: estudios en homenaje al profesor James S. Amelang, Madrid, UAM Ediciones. 

En algún momento entre 1898 y 1916, alguien (probablemente un periodista) le pidió a Emilia Pardo Bazán unas declaraciones sobre el regionalismo gallego. El borrador para una contestación -manuscrito e incompleto- se encuentra en el archivo de la Real Academia Galega. En su esbozo de respuestas, Pardo Bazán expresaba su admiración por que se le preguntase por ese tema después de toda una obra dedicada a Galicia, penetrada hasta la médula (decía) por el espíritu gallego. Su regionalismo cultural estaba, a su juicio, claro. Otra cosa era si le preguntaban sobre el regionalismo político. "Ahí tengo que pensar despacio».

En un momento en el que apuntaba el nuevo nacionalismo gallego (Beramendi 2007), Pardo Bazán reclamaba una definición precisa y clara del programa político de los regionalistas. Entonces, dice, sería posible que entre sus reclamaciones «hubiese algunas que [le] pareciesen sensatas y justas, como [se] lo [parecían] algunas de las que [elevaban] los regionalistas vascos y catalanes». ¿Era un movimiento separatista, unitarista, federalista pactista, absolutista, patriarcal? Una claridad en la definición que no se aplicaba a sí misma, a juzgar por declaraciones contradictorias entre sí como estas: «Hay en mí germen de un regionalismo marchitado en capullo»y «[S] oy regionalista por esencia, presencia y potencia» (Arquivo da Real Academia Galega, C254/31).

La pregunta es, por supuesto, qué entendía Pardo Bazán por regionalista y por qué se veía obligada, para su fingido pasmo, a responder a aquellas preguntas. Esta última cuestión queda algo más clara a través del segundo texto: un artículo de Antón Villar Ponte desde las páginas de A Nosa Terra. Idearium da Hirmandade da Fala en Galicia e nas colonias gallegas d'América e Portugal, número 31, del 20 de septiembre de 1917.

Se trataba de una "Carta aberta à Condesa de Pardo Bazán», con el encabezado de «Ilustre Enimiga». En ella se venía a poner en boca del periodista y escritor 
canario «Ángel Guerra» (José Betancort Cabrera) la siguiente afirmación: «[...] vostede non sentía a rexión, de que vostede ollando a rexión "cerebralmente" co iste xeito levábaa às suas notabres cuartillas. $\mathrm{O}$ marco da rexion [...] parecialle estreito, xa que cobizaba una fama e una groria universás, postas ó dorso d'un titulo de Castela». Ese desprecio por la región no solo era producto de su ambición desmesurada, sino que además se asentaba sobre la falsa premisa de que existía una «raza común hispana» cuyas manifestaciones espirituales y artísticas de orden regional «no son senón xeitos d'estructura accidental». Para quien acababa de liderar la creación de las Irmandades da Fala, aquella opinión de Pardo Bazán era pura fantasía: existía una raza gallega diferenciada y «Galicia eisiste con todal-as caraiterísticas d'unha nacionalidade mais acusada que a de moitos Estados nacionás» (Villar Ponte 2017).

La referencia a estos dos textos introduce las tres cuestiones que quiero discutir: la consideración de Emilia Pardo Bazán como una enemiga del galleguismo; la idea (en parte contradictoria con la anterior) de que se mantuvo neutral en el debate generado al respecto y, finalmente, que lo relevante en ese debate es su posición cultural y no tanto la política. En el primer y tercer casos, el argumento es que Pardo Bazán era incapaz de «sentir la región», como decía Villar Ponte, en la medida en que negaba «el hecho diferencial de Galicia y [...] la cultura y literatura gallegas" (Barreiro 2003). En el segundo, el planteamiento es que fue neutral porque rehuyó la polémica directa (Miralles 1997). Creo que en ambos hay argumentos y razones sólidos. Sin descartarlos, quiero defender las siguientes afirmaciones:

1. $\left.{ }^{\circ}\right)$ Resulta difícil desligar, porque nunca estuvieron desligados ni en Pardo Bazán ni en sus detractores, lo cultural y lo político.

2. ${ }^{\circ}$ Pardo Bazán rehuyó la polémica abierta, pero nunca fue neutral respecto al regionalismo, ni en lo cultural ni en lo político.

3. ${ }^{\circ}$ En su posición particular pesó un fuerte sentimiento de región anclado en una conciencia plena de los materiales culturales con los que se estaban construyendo, también en España, los Estados-nación europeos. Un proceso de carácter 
transnacional del que era muy consciente y que alumbró en ella un tipo de «nacionalismo defensivo» (Torrecilla 2003) que se miraba fundamentalmente en Francia. Un país que admiraba y al que, al tiempo, «se resistía» como modelo (Gabilondo 2009). Ese cruce de emociones, y no solo de razones, permeó su noción de España y de Galicia: sus limitaciones como nación, sus posibilidades y sus fantasmas.

4. $\left.{ }^{\circ}\right)$ La posición de Pardo Bazán evolucionó en el tiempo de una forma no necesariamente lineal y solo puede entenderse de manera cabal si se atiende a los contextos históricos del debate en España y en Europa. En ella pesaron los temores respecto a las implicaciones políticas de la existencia de una nacionalidad cultural gallega (o catalana, o vasca) distinta y opuesta a la de España.

5. $\left.{ }^{\circ}\right)$ Para entender esa posición no es posible limitarse al análisis de sus textos de crítica literaria, o de cariz político. Es fundamental analizar sus textos de ficción, sus novelas y cuentos. Esto es así porque Emilia Pardo Bazán era plenamente consciente de algo que impregna la historiografía actual sobre la construcción de las naciones y de las identidades nacionales: que la propia «configuración estética de las periferias» (Mainer 2010) y el surgimiento (o no) en ellas de una conciencia de nacionalidad propia no son -como a veces se ha creído ver- los distintos tamaños de las figuras de una matrioshka, sino un juego de espejos entre naciones y regiones que afecta a ambas (Archilés 2006; Núñez Seixas 2006). En ese juego de espejos, la novela fue un «mecanismo informal» de nacionalización (o desnacionalización) fundamental, con una enorme potencia intelectual y sentimental.

Resumo y aúno todo ello, avanzando en mi argumento global al respecto. Entiendo a Pardo Bazán como lo que hoy se llama «una constructora de nación», a nation builder española, profundamente anclada en el momento fundamental que, en toda Europa, significaron el último tercio del siglo XIX y las primeras décadas del siglo xx, hasta la I Guerra Mundial. En ese contexto, Emilia Pardo Bazán fue una nacionalista española plenamente moderna, consciente de lo que hacía y del papel esencial que en su tarea habrían de tener la región y 
el sentimiento de región. Toda la obra de Pardo Bazán está inundada de nación y de modernidad. Más exactamente, de discusión en torno a la nación y a la modernidad. Sin ellas no se pueden entender de manera cabal esa obra y esa vida. Como no se pueden entender sin la importancia que la supuestamente cerebral doña Emilia concedía a las emociones y a los sentimientos en las forjas de pertenencia; en lo que hoy los especialistas llaman «la construcción de los individuos nacionales» (Molina 2013). Ambas cuestiones, la nación (moderna) y la emoción, estuvieron relacionadas en su vida y en su obra con el problema de la ubicación que en todo ello se reservaba entonces a las mujeres y, más en concreto, a las mujeres escritoras. Su feminismo fue, en este sentido, pensado como un poderoso factor de nacionalización española y es, asimismo, fundamental para comprender mejor su posición particular respecto a Galicia y al regionalismo gallego. A ello habría que añadir, en un lugar estratégico crucial, la cuestión de la clase social.

Advierto que en mi interpretación no hay ningún intento de defensa de Pardo Bazán ante sus críticos galleguistas. Hay, sí, un intento de comprenderla dentro de la discusión de su época respecto a cómo se construyen las naciones, con qué materiales y de qué forma, qué papel se reserva en ellas para la razón y para la emoción, para la acción consciente y selectiva, para los conflictos de clase, para los hombres y para las mujeres; para la ubicación de la diversidad social y cultural, o su eliminación.

De mi tierra constituyó el primer estudio de conjunto sobre la literatura en gallego del momento, respecto a la que Emilia Pardo demostró un conocimiento y un aprecio estético indudables. El texto central «La poesía regional gallega» había sido compuesto como discurso en el homenaje a Rosalía de Castro celebrado en el Liceo de Artesanos de A Coruña, en septiembre de 1885. Su publicación tres años después era una intervención cultural y política plenamente calculada. Buscaba definir el lugar que la autora de Los Pazos de Ulloa podía (y debía) ocupar 
en el contexto de la polémica abierta por Gaspar Núñez de Arce contra el uso literario del catalán, el vasco o el gallego. No era esa la postura de Pardo Bazán. Su formación intelectual, social y emotiva en el tradicionalismo político y su propia concepción de la historia y de la literatura la ayudaban a ver las cosas de forma mucho más compleja. La tradición progresista de su familia aumentaba aún más esa complejidad.

Para Pardo Bazán, lo que entonces se llamaba «literatura regional» era poco más (y nada menos) que el puente que enlazaba «a las letras cultas con la poesía y arte del pueblo». Ese enlace se producía a través de la emoción, relacionada estrechamente con la infancia, implícitamente (pero nunca explícitamente) opuestas ambas al entendimiento de la madurez, identificado con la razón, con las «letras cultas» y con el castellano. Los poetas regionales «son la infancia, son la fe, son la ternura» (Pardo Bazán 1888).

Es necesario hacer hincapié en la identificación recurrente entre el uso del gallego y la emoción inarticulada, la infancia y el espacio doméstico. Algo, por cierto, que los historiadores catalanes han señalado también para la primera Renaixença (Marfany 2017). Galicia y el gallego vistos, en buena medida, como un territorio y una lengua prenacionales, pero no exóticos (y esto es importante) respecto a la nación adulta y a la lengua madura y europea que eran Espańa y el castellano. La emoción primordial, la unidad básica de la infancia, era la misma para Galicia y para España. En ese terreno Emilia Pardo Bazán era escasamente cerebral. Manuel Murguía, sin embargo, no creía en esa amalgama, en esa identificación emocional que colapsaba Galicia y España. Él era, como ella, un constructor de emociones nacionales. Su respuesta tardó, con todo, más de diez años en llegar. No se produjo hasta 1896, en una serie de agrios artículos en $\mathrm{La}$ Voz de Galicia (Murguía 2000).

En el núcleo de las airadas diatribas de Murguía se encontraba la construcción discursiva de la inevitable rivalidad entre Rosalía de Castro y Emilia Pardo Bazán. Todo su discurso estaba erigido sobre esa supuesta rivalidad que era, al mismo tiempo, literaria, política y femenina por cuanto representaba dos formas (una 
auténtica y otra monstruosa) de ser mujer, de ser gallega y de ser escritora. Para don Manuel era evidente que Emilia envidiaba la manifiesta superioridad literaria de Rosalía y había tratado, conscientemente, de empequeñecerla tildándola de «primer poeta regional», lo que implicaba, a juicio de su esposo, negarle el puesto destacado que merecía entre las poetisas españolas como Gertrudis Gómez de Avellaneda o Carolina Coronado. Murguía tenía razones, desde su punto de vista político y personal, para sentirse francamente irritado. El grado de mala fe o de soberbia por parte de Emilia Pardo es lo que estaría en cuestión. Lo interesante, en todo caso, no es la materia personal, sino la política. ¿Qué quería decir políticamente Pardo Bazán en aquel preciso momento y hablando de la única autora (o autor) que podía competir con ella en el canon gallego y español?

En primer lugar, algo que ponía en tensión toda su concepción de la historia, de raíz básicamente tradicionalista y antiilustrada. Quería decir que existía una línea de progreso, una flecha del tiempo y una suerte de selección natural darwinista para las naciones y para las lenguas. Seguía así las tesis «progresistas» de la mayor parte del liberalismo europeo, incluidos sus representantes más radicales. La vía del progreso para las identidades y las lenguas «regionales» era hacer causa común con las «nacionales», integrarse en ellas, aportar a ellas su savia vital e intelectual. La nación española era el gran río al que habrían de contribuir todos los afluentes. Todas las emociones y todos los esfuerzos.

Lo interesante es que esa metáfora le permitía integrar la diversidad e incluso celebrarla. Voy a centrarme en los años ochenta, pero creo que esa apuesta (nacionalizadora, a su juicio) puede rastrearse en sus discursos regeneracionistas después del desastre de 1898, en especial en el que pronunció en el Ateneo de Valencia en diciembre de 1899 (Pardo Bazán 1899). Quizás haya ocasión en el debate para tratar esa cuestión.

Por una parte, Pardo Bazán era demasiado inteligente y había estado demasiado en contacto personal e intelectual con el tradicionalismo político como para tener una visión roma y lineal del progreso. Desde su punto de vista, el «resurgir» de la literatura en gallego era, sobre todo, un movimiento de resistencia (plenamente 
moderno, en realidad) a la tendencia homogeneizadora de los siglos XVIII y XIX que debía entenderse en un contexto europeo general. Podía considerar el renacer del gallego en los medios cultos como un "caso de atavismo», pero planteaba al respecto matizaciones importantes que la distinguían de sus colegas más estrechamente castellanizantes. Sobre todo, y no es irrelevante en absoluto, porque creía que se podía hacer buena, muy buena, literatura en lenguas distintas al castellano y que, además, de acuerdo con su propia concepción literaria naturalista, eso era lo que había que hacer -al menos en algunos casos (Pardo Bazán 1888)-.

Aquí merece la pena reflexionar, con brevedad, sobre su relación con la literatura en catalán, que admiraba. Una relación que fue especialmente estrecha con la obra de Jacint Verdaguer, con el crítico Josep Yxart y con el novelista Narcís Oller, implicados todos ellos en la Renaixença del catalán como lengua literaria y, más en concreto, en los dos últimos casos, del «catalá que ara es parla». Para Yxart, Emilia Pardo Bazán se había convertido en parte sustancial de la gran regeneración del castellano que se estaba operando en aquellos momentos a través de la novela. Un camino que ya habían recorrido otras literaturas europeas, y en buena medida también las «lenguas provinciales» como el catalán, cuyo objetivo era superar el divorcio rancio entre "la lengua de los libros y la lengua hablada». Por eso había sido capaz de valorar a los poetas gallegos "de un modo íntimo" y de comprender el «principio vivificador» que proviene de las llamadas «literaturas regionales» (Yxart [1889] 1996).

Esa era la actitud que le permitía apreciar con intensidad la literatura catalana, leyendo directamente en catalán. Era una cuestión de sintonía literaria y de respeto por una lengua que, frente a opiniones que creía poco o perversamente informadas, tenía a su juicio todos los registros necesarios para hacer arte y para contribuir, desde la diversidad, a la construcción de la nación española. Aquí podían retroalimentarse los legados tradicionalista y progresista (en la versión descentralizadora y provincialista del primer progresismo) de su formación literaria y política. Un tema que no puedo desarrollar aquí, pero que merece ser tratado con cuidado para entender mejor la complejidad de la propuesta nacionalizadora, española, de Emilia Pardo. 
En todo caso, en su valoración de las literaturas en lenguas distintas al castellano fue bastante más respetuosa que otros escritores como Núñez de Arce o Galdós. Hasta cierto punto podía estar de acuerdo, al menos durante un tiempo, con el Juan Valera anterior a 1868: «En resolución, yo miro como riqueza envidiable, que no debemos perder, ni confundir, ni mezclar, el que tengamos tres y no sólo una lengua literaria; pero me inclino a creer que todo español debe entender y estudiar las tres, seguro de que con ello completará y hermoseará más la que él hable y escriba, sin desnaturalizarla por eso» (Oller 1962; texto original de 1913-1918).

Para Pardo Bazán todas las literaturas regionales españolas (incluida la castellana y andaluza) eran producto de la historia. Por eso, entre ellas había sustanciales diferencias. Existían regiones como Galicia cuya lengua antigua había venido a menos y se había perdido para las clases cultas y para la literatura, quedando confinada al pueblo. En otras regiones, notoriamente Cataluña, el catalán nunca se perdió del todo para la literatura y «todas las clases sociales, para todos los usos de la vida, se [servían] del habla provincial». Por eso, lo que era natural en catalán era en buena medida artificioso en gallego. A diferencia del provenzal o del catalán, «el gallego no lo [hablaban] quienes lo [escribían]» o, incluso, ni lo hablaban habitualmente ni lo escribían (como era el caso de Manuel Murguía) quienes se erigían en sus defensores. Esto tenía también sus ventajas, pues, frente a la Renaixença, «la literatura gallega [conservaba] más su carácter propio, y hasta el día se [hallaba] bastante exenta del influjo francés, tan poderoso en Cataluña [...]». En todo caso, y esto es fundamental, para ella «la distinción entre dialectos y lenguas nacionales es artificiosa y no toca a la esencia, sino a la forma de los lenguajes». La distinción se concibe, estrictamente, en términos históricos despojados de cualquier esencialismo. A la historia había que atenerse y en torno a ella había que entender el desarrollo de una lengua, su abandono, su hegemonía o su derrota.

Como he dicho al principio, en la evolución de su pensamiento es fundamental atender a los contextos de discusión en torno a la cuestión regionalista y 
nacionalista. Dice Xosé Ramón Barreiro -en una de sus múltiples intervenciones imprescindibles sobre Pardo Bazán- que «la cuestión del reconocimiento o no de la lengua y de la literatura regional no es directamente política sino cultural» y que lo grave es que Pardo Bazán negase ese reconocimiento cultural a la literatura en gallego. «Es en este punto en el que debemos centrar la cuestión y no en el tema, que creemos sin interés alguno, de lo que pensaba dońa Emilia sobre el regionalismo político gallego». No considero posible disociar ambos aspectos. No, desde luego, en el debate de los últimos decenios del siglo xix y principios del xx. Creo también que no puede decirse que Emilia Pardo no comprendiese «estimativamente lo que la lengua y la literatura gallega significaba en la construcción de una identidad» (Barreiro 2003). Lo comprendía a la perfección en la medida en que era consciente del enorme peso político (es decir, de acción sobre la historia) que tenía la interrelación profunda que gente como Murguía estaba fraguando entre la galleguidad y la literatura en gallego.

Pardo Bazán sabía (porque era lo que ella estaba haciendo) que las lenguas también se construyen (y se destruyen) y alcanzan o no una capacidad de absorción o de marginación de otras. Era consciente del papel crucial que la lengua, y las emociones construidas en torno a ella, desempeñan en la construcción de una nación. Se trataba de un proceso histórico, político, que tenía que ver con las relaciones de poder culturales y con la acción «informal» de gente como ella misma o como Murguía.

Emilia Pardo estaba empeñada en la construcción de una nación y de una lengua (la espańola) que (y esto es importante) no eran algo acabado y claro, sino un proceso laborioso y lleno de potenciales culs-de-sac, de ambivalencias y de dudas, de posibilidades abiertas y de horizontes inciertos que afectaban tanto a Galicia como a Espańa. Es en este contexto, profundamente inestable, en el que advirtió que las «literaturas regionales» podían convertirse en «complicaciones» para su propio proyecto nacional. Si Valera (antes de 1868) vio una oportunidad para España en el reconocimiento de su diversidad lingüística, Emilia Pardo Bazán (escribiendo en los años ochenta y noventa del siglo xIx) vio la posibilidad 
abierta de nacionalismos conflictivos entre sí. Se puede estar de acuerdo o no con ella, pero en ese aspecto concreto no se equivocaba porque advirtió que todo lo cultural es político y que toda acción política se asienta sobre supuestos culturales que son, también, producto de la historia y no de la naturaleza, ni de la raza, etc. (Para consultar a Murguía en este último y decisivo aspecto, ver Máiz 1984).

Por lo tanto, a mi juicio, la cuestión que hay que evaluar, precisamente, es el calado político de su comprensión del carácter en muy gran medida interrelacionado del proceso de construcción de los Estado-nación europeos y de las resistencias a ese proceso. Una dinámica general y común a «la modernidad» occidental y a sus desasosiegos. Es en este contexto en el que le escribió a Narcís Oller en 1886 -cuando los ecos del Memorial de Greuges en defensa de los intereses morales y materiales de Cataluña aún no se habían apagado-:

[M]i españolismo se acentúa. Sí, yo soy poeta ante todo [...][,] pero no se ha de menester de gran dosis de poesía para tener una mediana ración de orgullo y querer pertenecer a una gran Nación mejor que a un estadillo menesteroso... y que (no lo dude usted, amigo mío) andaría manejado por cuatro galopines, pues ustedes, los que valen, siempre se quedarían detrás de los mangoneadores. Eso si se salva del yugo extranjero. Vade retro el regionalismo.

Así, aun sintiéndose emocionalmente desarmada por la potencia estética del catalán y del gallego, temía «lo que en el terreno político representa la literatura regional [...], que lleva en sí un germen de separatismo, germen poco desarrollado todavía, pero cuya presencia es imposible negar, y que acaso sea el único fruto político y social de este florecimiento» (Oller 1962; texto original de 1913-1918).

El problema de la respuesta de Murguía a estos planteamientos de 1886-1888 es que el autor no solo fue incapaz de escapar a su resentimiento personal, sino que, por añadidura, articuló dicha respuesta de forma profundamente sexista. La amparó además -a mi juicio, de manera muy sesgada y descontextualizada- en las 
propias palabras de Rosalía sobre la ligereza y «debilidad innata» del pensamiento de la mujer o su incapacidad "para el duro trabajo de la meditación». Algo que orientaba sus facultades, naturalmente, hacia la poesía y, en su caso, debía hacerlo (por su proximidad, en cuanto mujer, con la tierra y lo natural) hacia la poesía en gallego. En la penumbra, o incluso en la censura completa, quedaron las dudas de Rosalía sobre cuál había de ser su lengua literaria y cuánta la importancia que otorgó a su prosa en castellano.

Pardo Bazán, sin embargo, había hablado bien alto y, según Murguía, de forma absolutamente insolente. Tanto como para creer que, «en los dominios del arte y de la ciencia, nada le estaba vedado, que en ellos podía entrar como vencedora». El resultado de esta monstruosidad, esa impertinencia antinatural, era una «merlette» literaria, aupada por ventajosas relaciones coruñesas y madrileñas, una simuladora de talento, una plagiófila compulsiva, una "Bubarda y Pecucheta», una grafómana empeñada en «escribir de todo cuanto escribieron otros antes que ella». "Y no la culpo por eso -añade Murguía-. Está en su condición de hembra». Una condición que, sin embargo, transgredía una y otra vez con su frialdad, con su ambición, con su soberbia, con su congénito prosaísmo. Ni siquiera había logrado emocionar con los poemas a su hijo Jaime: « $i$ Una madre que no logra enternecernos cuando habla de su hijo!... Es lo que faltaba por ver». Emilia Pardo no solo carecía de «las dos condiciones precisas en la mujer poeta: la imaginación y el sentimiento", sino que además traicionaba su condición de gallega al romper lo que distinguió siempre a su literatura: «[...] una especial dulzura de expresión, [...] su verdadera característica. Su nota dominante es el sentimiento; faltar a ella es faltar a algo propio y esencial, negarse a ser de la raza a que uno pertenece

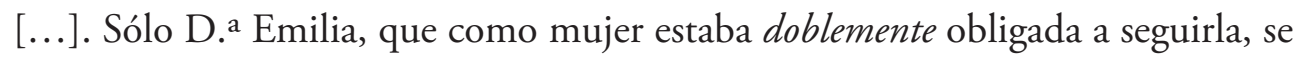
aparta del todo de la general corriente» (Murguía 2000). Merece la pena destacar en cursiva ese doblemente.

La ira y el sexismo de Murguía acaban por cerrar el círculo y aceptar aquello mismo que le había irritado en la identificación de Pardo Bazán entre lo gallego y lo sentimental, lo emocional y lo femenino. Sus artículos de 1896 resultan en 
este sentido más interesantes que un mero exabrupto y una muestra algo extravagante de resentimiento personal. Tienen una cualidad especial para hacernos entrever la profunda identidad, y la jerarquía, que su autor establece entre Galicia y lo femenino, por una parte, y el galleguismo cultural y político encarnado en la varonil defensa que Murguía representa, por otra. De esta manera, la supuesta rivalidad entre Emilia y Rosalía aparece como la que se establece entre una virago (una mujer doblemente traidora a su naturaleza y a su patria) y la auténtica mujer (sufriente, saudosa, patriótica), defendida por un hombre frente a otro hombre: el nacionalismo gallego frente al español. Murguía (que escribe en castellano e insiste en que Rosalía escriba en gallego) es quien define, quien otorga (o niega) identidad sexual y estatuto artístico, canónico, nacional, a ambas: quien se erige en autoridad al respecto.

No voy a desarrollar más esta cuestión del sexo y del género y su implicación en la definición y conformación del canon (gallego y español), pero la considero sustancial (Pereira-Muro 2012). Sustancial porque, entre otras cosas, subvierte las jerarquías e incluso las identidades masculina y femenina en la construcción nacional, lo cual afectaba no a Galicia o a Espańa únicamente, sino a la totalidad de los países de su entorno, cuando menos. Tan solo quiero apuntar lo siguiente. Manuel Murguía tenía, en parte, razón al creer que el horizonte de Pardo Bazán era el mismo que el suyo y que tenía «el soberano deseo de regentar [...] la literatura gallega, y algo más». Ese «algo más» era en realidad lo verdaderamente importante. A diferencia de lo que ocurría en el caso del pontífice del regionalismo, el horizonte de la autora de Los Pazos de Ulloa hacía ya tiempo que había dejado de ser (en exclusiva) Galicia. Era en España, y en concreto en Madrid, donde no dejó nunca de ejercer de gallega neta y clara. En este sentido, mucho más profundo, que entendía la construcción cultural, imaginativa, de la región como una forma de hacer patria, de re-crear la identidad nacional española, Emilia Pardo Bazán sí competía con Manuel Murguía como líder de un regionalismo que él construía, cada vez más, en conflicto con la nación (emoción) española y ella no. 
De hecho, la apuesta de Pardo Bazán era (como Murguía vio inmediatamente) competidora política y cultural de la suya. Entre otras cosas, porque dońa Emilia no se conformaba (como tampoco lo hizo Rosalía, aunque calló más) con ser la encarnación emotiva, sensible, de la tierra sońada, sino una de sus artífices. Alguien que, como él, quería delinearla, definirla y orientarla.

En ese proceso de definición -y con ello voy a concluir-, España y Galicia resultan identidades no solo profundamente ligadas entre sí, sino (por ello mismo) también profundamente inestables. No voy a entrar en el tema de la «inestabilidad» de España en la obra de Pardo Bazán porque lo trataré más por extenso en otro lugar. Sí quiero apuntar alguna reflexión más sobre Galicia.

Antes, quiero advertir que mantengo serias reservas respecto a la aplicación de la crítica poscolonial a la cuestión nacional en contextos no estrictamente coloniales. Sin embargo -como han demostrado Xavier Andreu (2016) para España o Helena Miguélez-Carballeira (2013) para Galicia, por citar textos útiles y recientes, aunque muy distintos-, la perspectiva de la crítica poscolonial tiene una capacidad notable para iluminar los conflictos y los diálogos de representación de las identidades nacionales. En este caso, me refiero concretamente a la forma en que se cruzan el diálogo (y el conflicto) entre la identidad nacional española y las europeas hegemónicas con los significados e identidades formulados en el marco de los diversos proyectos nacionales dentro de la península. Desde hace décadas, los historiadores venimos insistiendo en el carácter relacional de las identidades de raza, género, nación o clase social. No hay identidad sin relación y sin un Otro que es construido al tiempo que el propio yo. Esa relación, que implica dos direcciones, es siempre jerárquica. De hecho, una posición de poder económico, social o político se define en buena medida por su capacidad para imponer identidades subalternas. Aquellas en las que las imágenes que el Otro fabrica para legitimar su poder se interiorizan y se reproducen como inferiores y subordinadas. 
La identidad de clase ha desaparecido con demasiada rapidez, y completamente, del análisis de los historiadores en los últimos años. También, y de una manera peligrosa, a mi juicio, de la historiografía que se ocupa de los procesos de construcción de identidades nacionales. Voy a plantear esa cuestión a través de una novela de gallegos ( $y$, más en concreto, de gallegas) en Madrid, Morriña (1889). Una de las obras más delicadas y lúcidas de Pardo Bazán, llena de ternura y de sentido del humor, y también de crueldad. No fue así considerada, en el momento de su publicación, por Luis Alfonso y Clarín, para quienes era una novela sosa, cuyo asunto (dice el primero) no interesaba (Alfonso 1889). «Puede hacerse interesante a un aldeana, a una mujer de la clase más humilde [...], pero a una criada es mucho más difícil» (Alas 1889). Una criada dulce y sumisa que, sin embargo, «se sale de su clase» al creer que los favores del señorito pueden tener algo que ver con el amor. ¡Una criada romántica! (casi una contradicción en términos), llena de morrińa por una tierra, Galicia, que ni siquiera en el recuerdo puede ser un refugio para ella, porque es desde allí desde donde viene la vergüenza de su nacimiento como hija bastarda de un cura y de su sirvienta.

Esclavitud carece de cualquier recurso y todo en su entorno parece conducirla a repetir una y otra vez la experiencia traumática de las mujeres del pueblo: la seducción, la pérdida de la virginidad, el abandono, los hijos bastardos. Un tema que siempre había interesado a Pardo Bazán cuando escribía (con indignación) que los señoritos de su clase salían a la búsqueda de las chicas del pueblo, especialmente de las criadas, como si saliesen a cazar perdices. Un tema que aquí se hace más complejo a través de la discusión sobre las buenas intenciones de la dueña de la casa, la dama gallega dońa Aurora Nogueira de Pardińas, que acoge a Esclavitud a pesar de su origen, la defiende y la ayuda, frente a las opiniones de buena parte de su entorno.

Finalmente, sin embargo, «en holocausto a la moral», cuando ve el interés que la criada despierta en su único y adorado hijo - un petimetre consentido carente de cualquier personalidad reconocible-, aleja a Esclavitud de su casa y se marcha con él a Galicia, dejándola a ella atrás, en un Madrid desolado. Sin 
patria. A Esclavitud no le queda siquiera el convento (un recurso para señoritas descarriadas) y planea suicidarse. No tiene la potencia personal, ni la capacidad para la rebeldía, de La Tribuna (1883). No tiene, por supuesto, la riqueza y la cultura de la marquesa de Andrade en Insolación (1889). No es una obrera o una señora, es una criada. Alguien de quien se dudaba, incluso, que pudiese ser materia novelable.

Se requería alguien como Pardo Bazán, que siempre vivió entre dos orillas, para que lo fuese. Para que, por medio del caso prosaico, sórdido, del despertar a la sexualidad de los señoritos a través de las criadas, se pudiese pensar en cómo el género y la clase rompen las costuras de la nación y la cuestionan. Una reflexión singular y hondamente conmovedora que se logra invirtiendo, o al menos cuestionando, la dirección única de la mirada, dando voz a la falta de voz de Esclavitud.

Todos en la tertulia de la viuda del magistrado Pardińas hablan de ella y sobre ella, de sus orígenes y de su destino, de sus posibilidades de escapar o no a él. No escapa, pero no lo hace por inmoralidad o sumisión social y racialmente congénita. A diferencia de Murguía, por ejemplo (Máiz 1984), Pardo Bazán dudó siempre de lo racialmente congénito. Esclavitud no escapa a su destino porque Aurora Nogueira de Pardiñas, sus contertulios y sus amigos consideran que a quien hay que salvar de aquel «resbalón» es al joven Rogelio. La criadita gallega no se suicida por culpa del «sombrío humor de la raza céltica». Todos los días y en cada provincia de Espańa, dice la autora, la prensa traía noticias de suicidios así. No era un problema de tierra o de raza. Era un problema de clase. Esclavitud no es seducida, abandonada y maltratada porque sea gallega, sino porque es una criada. Esclavitud -que es el sujeto subalterno radical: aquel que no puede hablar de sí mismo (Spivak [1985] 2010)-, en todo caso, planea matarse porque es su única manera posible de hablar, de quedar en la memoria, de impregnar con su tragedia el respetable mundo de esos señores gallegos que han venido observando su evolución y su caída como si fuese un torneo o un ensayo clínico.

La Galicia de Pardo Bazán -a pesar del uso ruralista y localista que se ha hecho de su obra- no es «una nación sentimental» en el sentido del estereotipo español 
(y gallego) que ha analizado Helena Miguélez-Carballeira. Es una Galicia dura y compleja, atravesada por conflictos de clase del todo modernos que trascienden -en la visión de Pardo Bazán- la capacidad inclusiva de una nación, o dos naciones, profundamente ligadas entre sí y profundamente inestables, inseguras de sí mismas. Buena parte de la singularidad de su obra, de su Galicia, reside, a mi juicio, precisamente en la capacidad para ir más allá de la celebración más o menos pintoresca de lo rural, lo local, lo regional, a la que recurrieron otros escritores de la Restauración y también de los regionalismos más o menos protonacionalistas (Labanyi 2011). A ella lo que le interesó fue deshacer la oposición -que en buena medida permeaba la obra de muchos de esos escritores- entre una modernidad neurótica y degenerada, encarnada en la nación moderna, y en concreto en Madrid, y un instinto natural, un retiro campestre, saludable y virtuoso, depositado en la región. Cuestionó, especialmente en sus novelas, la dicotomía entre la nación moderna, artificial, y la región anclada en el pasado, en la tradición, en la vieja lengua y en la vieja tierra, en lo esencial, en lo natural.

Más aún, y esto es lo verdaderamente original, planteó la posibilidad de que no existiese una respuesta única, totalizadora y real para el malestar en la modernidad que atañía a ambos polos de esa supuesta dicotomía. La verdad de la nación que todo lo resuelve -y las soluciones individuales y colectivas inscritas en su búsqueda- eran siempre relativas y, por lo tanto, estaban sujetas a discusión. El resultado de todo ello fue una problematización de las ilusiones en torno a lo natural y lo esencial que, a mi juicio, no tiene parangón en ningún otro novelista de su generación. Especialmente por lo que se refiere a su capacidad de abrir el debate sobre la importancia de la clase social y de la posición de las mujeres, de la supuesta naturaleza femenina, como síntomas cruciales de las grandes contradicciones internas del liberalismo, la democracia y el nacionalismo. Por eso es una intelectual imprescindible para comprender las tensiones sociales, políticas y culturales del último tercio del siglo XIX en España y en Galicia: sus desasosiegos y sus fantasmas son plenamente modernos. 


\section{REFERENCIAS BIBLIOGRÁFICAS}

Alas, Leopoldo (1889): «Morriña», Madrid Cómico, 9 de noviembre.

Alfonso, Luis (1889): «Morriña, de Emilia Pardo Bazán», La Época, 2 de diciembre.

Andreu, Xavier (2016): El descubrimiento de España: mito romántico e identidad nacional, Madrid, Taurus. Andreu, Xavier (2017): Género y nación en la España contemporánea, dosier, Ayer, 106.

ArCHiLÉs, Ferran (2006): «La novela y la nación en la literatura española de la Restauración: región y provincia en el imaginario nacional», en Carlos Forcadell / María Cruz Romeo (eds.), Provincia y nación: los territorios del liberalismo, Zaragoza, Institución Fernando el Católico, 161-190.

ArCHILÉs, Ferran (2013): «Lenguajes de nación. Las “experiencias” de nación y los procesos de nacionalización: propuestas para un debate», Ayer, 90, 91-114.

Barreiro, Xosé Ramón (2003): «Emilia Pardo Bazán en su tiempo histórico», en Ana María Freire (ed.), Estudios sobre la obra de Emilia Pardo Bazán: actas de las jornadas conmemorativas de los 150 años de su nacimiento, A Coruña, Fundación Pedro Barrié de la Maza, 15-38.

Barreiro, Xosé Ramón (2012): Murguía, Vigo, Galaxia.

Beramendi, Justo G. (2007): De provincia a nación: historia do galeguismo político, Vigo, Edicións Xerais de Galicia.

Gabilondo, Joseba (2009): «Towards a Postnational History of Galician Literature: On Pardo Bazán’s Transnational and Translational Position", Bulletin of Hispanic Studies, 86:2, 249-274.

Labanyi, Jo (2011): «La problematización de lo natural: Los Pazos de Ulloa (1886) y La madre naturaleza (1887) de Pardo Bazán», en Género y modernización en la novela realista española, col. Feminismos, Madrid, Cátedra, 409-465.

Mainer, José-Carlos (2010): Historia de la literatura española: 6. Modernidad y nacionalismo,1900-1939, Barcelona, Crítica.

Márz, Ramón (1984): «Raza y mito céltico en los orígenes del nacionalismo gallego: Manuel M. Murguía», Revista Española de Investigaciones Sociológicas, 25, 137-180.

Marfany, Joan-Lluís (2017): Nacionalisme espanyol i catalanitat: cap a una revisió de la Renaixença, Barcelona, Edicions 62.

Miguélez-Carballeira, Helena (2013): Galicia, a Sentimental Nation: Gender, Culture and Politics, Cardiff, University of Wales Press.

Miralles, Enrique (1997): «La neutralidad de Pardo Bazán ante el regionalismo gallego: elusión de una polémica», en José Manuel González Herrán (ed.), Estudios sobre Emilia Pardo Bazán: in memoriam Maurice Hemingway, Santiago de Compostela, Universidade, 224-238.

Molina, Fernando (2013): «La nación desde abajo. Nacionalización, individuo e identidad nacional», en Alejandro Quiroga / Ferran Archilés (eds.), La nacionalización en España, dosier, Ayer, 90, 39-63.

Murguía, Manuel (2000): Murguia e La Voz de Galicia, ed. de Tucho Calvo, A Coruña, La Voz de Galicia, 33-120.

NúNÉz Seixas, Xosé M. (ed.) (2006): La construcción de la identidad regional en Europa y en España (siglos XIX $y$ XX), dosier, Ayer, 64 .

Oller, Narcís (1962): Memòries literàries: història dels meus llibres, Barcelona, Aedos.

Pardo BazÁn, Emilia (1888): De mi tierra, A Coruña, Tipografía de la Casa de Misericordia. 
Pardo BazÁn, Emilia (1899): Discurso inaugural del Ateneo de Valencia, pronunciado en el Paraninfo de la Universidad de Valencia la noche del 29 de diciembre de 1899, Madrid, Administración de S. Bernardo, 37 principal.

Pardo BazÁn, Emilia ([1889] 1999): Obras completas, vol. II: Los Pazos de Ulloa; La madre naturaleza; Insolación; Morriña, Madrid, Fundación José Antonio Castro.

Pardo Bazán, Emilia (s. f.): «Entrevista a Emilia Pardo Bazán», A Coruña, Arquivo da Real Academia Galega, C-254/31.

Pereira-Muro, Carmen (2013): Género, nación y literatura: Emilia Pardo Bazán en la literatura gallega y española, West Lafayette, Indiana, Purdue University Press.

SARDÁ, Juan (1889): «Insolación (Historia amorosa), por Emilia Pardo Bazán», La España Moderna, V, 31 de mayo, 179-185.

Sprvak, Gayatri ([1985] 2010): «Can the Subaltern Speak?: Speculations on Widow Sacrifice», en Rosalind C. Morris (ed.) Can the Subaltern Speak?: Reflections on the History of an Idea, New York, Columbia University Press.

Torrecilla, Jesús (2003): «Un país poético y una polémica: las interioridades de Insolación», Hispanic Review, 71:2, 253-270.

Tsuchiya, Akiko (2011): Marginal Subjects: Gender and Deviance in Fin-de-Siècle Spain, Toronto, University of Toronto Press.

VAlera, Juan (1996): El arte de la novela, edición, prólogo y notas de Alfonso Sotelo Vázquez, Barcelona, Lumen.

Villar Ponte, Antón (1917): "Carta aberta á Condesa de Pardo Bazán», A Nosa Terra, 31, 20 de septiembre.

YXART, Josep ([1889] 1996): «De mi tierra, por Emilia Pardo Bazán», La España Moderna, IV, en Rosa Cabré (ed.), José Yxart: critica dispersa (1883-1893), Barcelona, Lumen, 110-117. 